\title{
Resenha Trading Voices: The European Union in International Commercial Negotiations*
}

Sophie Meunier. Princeton, Princeton University Press, 2005, 238 páginas.

\section{Rogério de Souza Farias**}

\begin{abstract}
Robert S. Strauss, um dos negociadores mais hábeis dos Estados Unidos no The General Agreement on Tariffs and Trade (GATT) (em português, Acordo Geral sobre Tarifas e Comércio), afirmava, com a autoridade de sua experiência na Rodada Tóquio, que o caminho mais rápido para o fracasso em negociações comerciais internacionais é excluir as forças políticas domésticas desse processo. De fato, a necessidade de criar coalizões de constituintes para apoiar o processo negociador levou-o a devotar mais tempo negociando com o Congresso americano, empresários e trabalhadores do que nas negociações internacionais. Strauss foi considerado um "animal político", no sentido de que seu carisma e sua vasta rede de contatos possibilitaram o sucesso das negociações, trabalhando na margem entre os constrangimentos internos à aceitação do acordo internacional e as necessidades externas de manutenção de um comércio internacional menos susceptível a pressões protecionistas (Strauss, 1987:ix-xi; Dryden, 1995:208).
\end{abstract}

\footnotetext{
* Resenha recebida em março e aceita para publicação em abril de 2006.

**Mestrando em Relações Internacionais pela Universidade de Brasília (UnB).
}

CONTEXTO INTERNACIONAL Rio de Janeiro, vol. 28, n 1, janeiro/junho 2006, pp. 269-276. 
Uma das lições do negociador americano é a importância das interações que se deslocam no eixo doméstico/externo e que criam demandas crescentes para os analistas das relações internacionais compreenderem como se desenvolvem processos que não podem ser explicados sem uma análise das interações entre política doméstica e internacional (Moravcsik, 1993:4). No campo específico das negociações comerciais multilaterais, essa abordagem não é novidade, pois trabalhos seminais já lidavam, com variado grau de sucesso, com esses parâmetros (Aaronson, 1996; Destler, 1995; Evans, 1971; Preeg, 1970; Winham, 1986).

De certa forma, esses livros avançam a idéia de que a compreensão da atuação americana no sistema multilateral de comércio deve levar em conta grupos de interesses e forças institucionais domésticas, e não somente argumentos sistêmicos. Se, por um lado, o caso americano já foi muito estudado, por outro, a análise de como forças institucionais e grupos de interesses são importantes para explicar o resultado da interação de barganhas em outros países ainda é limitada, mesmo em países desenvolvidos (Nau, 1989:3). Para se ter idéia, se somarmos teses de doutorado e livros, em língua inglesa, que tratam de aspectos domésticos da inserção do Canadá, Austrália, Japão e União Européia no GATT, teremos menos de duas dezenas de trabalhos de grande relevo (alguns exemplos são Capling, 2001; Vahl, 1997; Davis, 2003; Stone, 1984; Hart, 1998; 2002; Manyin, 1999; Searight, 1999; Blaker et alii,: 1978) ${ }^{*}$.

\footnotetext{
* As fontes para este levantamento foram os sistemas EBRARY, JSTOR, EBSCO, OVID, Proquest Academic Research Library, Proquest Dissertations e a Thesis/Library of Congress Online Catalog. Foram realizadas visitas à Biblioteca da Universidade de Maryland (EUA) e à Biblioteca do Congresso Americano para a harmonização e prospecção das referências encontradas entre dezembro de 2005 e janeiro de 2006. Percebeu-se, com essa pesquisa, que esses sistemas só alcançam, com acurácia, no máximo referências produzidas após a década de 1970. Sendo assim, foram utilizados a referência The GATT Bibliography e os seus dezesseis suplementos, publicados pela secretaria do GATT para abarcar o período de 1946 a 1970. Para o período que vai de 1970 a 1976 foi utilizada a compilação feita por Richard Ford. Tanto a bibliografia editada pelo GATT como a compilada por Richard Ford estão disponíveis no site $<$ http://gatt.stanford.edu>.
} 
A lacuna mais crítica, contudo, talvez seja a dos trabalhos que lidam com a atuação da União Européia em negociações comerciais multilaterais - a entidade mais importante no comércio internacional após os Estados Unidos. De fato, desde 1958 a integração européia tem sido peça-chave na própria evolução do GATT e é por esta razão que o trabalho de Sophie Meunier já é uma contribuição louvável, tendo lugar cativo na bibliografia de apoio das disciplinas de comércio e negociação internacional. O livro, contudo, não vem trabalhar em terreno estéril, já que não é a primeira produção da autora sobre o tema (Meunier e Nicolaidis, 1999; Meunier, 2000; 2003). Com efeito, desde sua tese de doutorado, Sophie Meunier preocupa-se com os fundamentos do processo decisório europeu na arena comercial e como as instituições européias impactam na harmonização das posições dos países-membros para a formação de uma única "voz" nas negociações do sistema GATT (em português, Organização Mundial do Comércio - OMC).

O livro procura responder questões semelhantes, principalmente quais são os efeitos esperados da transferência de autoridade para a formulação da política comercial para o nível supranacional. Para tanto, de acordo com a autora, uma abordagem institucionalista será o diferencial relevante no texto, principalmente pela tentativa de rompimento de uma ortodoxia central nos estudos sobre a ação européia no sistema multilateral de comércio. Sophie Meunier, assim, afirmará que, geralmente, esses textos explicam a força externa européia por meio da premissa de que os resultados distributivos de negociações são definidos por categorias como poder, preferências, natureza da negociação e habilidade dos negociadores - "sendo a tese de que quanto mais integrado, mais poder o arranjo regional poderá exercer" (2000:40) a idéia subjacente à maioria das variáveis.

Dessa forma, de acordo com a autora, a estrutura institucional complexa da União Européia e a necessidade de existir arranjos processuais internos para negociar acordos comerciais internacionais com 
uma única vozé que teriam um impacto importante, e por vezes decisivo, nas negociações comerciais. Utilizando uma idéia avançada por Thomas Schelling e Robert Putman, a autora vai afirmar que nem sempre um negociador que tem liberdade para atuar consegue resultados mais vantajosos. Na verdade, divisões internas e instruções limitadas podem ser mais vantajosas que a liberdade completa para se ter maior poder de barganha em negociações comerciais multilaterais - ou seja, as instituições supranacionais nas quais as preferências dos Estados-membros são agregadas influenciam os resultados.

Meunier utilizará duas variáveis que, dentro da categoria "estrutura institucional", contribuem para explicar o poder de barganha externo na União Européia. A primeira é o nível de competência supranacional do bloco, que seria a conjunção dos procedimentos de votação internos e o grau de delegação supranacional da questão. Dessa forma, ao utilizar regras de unanimidade, por exemplo, como procedimento de decisão interno para solucionar uma questão, seria dado mais peso às posições dos membros que têm mais a perder em uma determinada questão do que se fossem utilizados procedimentos de maioria. $\mathrm{O}$ grau de delegação de uma questão, por seu turno, significa o quanto uma competência foi delegada pelos Estados-membros aos negociadores da Comissão Européia.

A segunda variável do trabalho da autora é a natureza do contexto negociador. Assim, a distribuição de preferências da União Européia com os seus parceiros negociadores determina situações negociadoras distintas que, por seu turno, influenciam o impacto dos mecanismos institucionais do bloco em sua capacidade externa de barganha.

Apesar de parecer confuso e abstrato, a autora realizará quatro estudos de negociações da União Européia com os Estados Unidos para testar a correlação dessas duas variáveis na explicação de que o poder de barganha do bloco europeu não é uma função linear de seu grau de integração. 
Cabe aqui ressaltar dois casos de especial relevo: a negociação agrícola da Rodada Kennedy (1963-1967) e a negociação agrícola da Rodada Uruguai (1993-1994).

"No primeiro caso, a crise da cadeira vazia, na qual os franceses levaram a suspensão de todas as atividades da Comunidade Econômica Européia em meados de 1965, serviu para mudanças no processo decisório do Conselho Europeu, em que os membros eram autorizados a manter posição de veto se uma questão de vital importância para eles fosse decidida desfavoravelmente" (2000:91).

Assim, se no início da Rodada Kennedy a pressão americana apontava para uma mudança substantiva da política agrícola européia, no momento subseqüente, a França, que mantinha a ameaça de veto sobre a questão, conseguiu manter uma vigilância dos negociadores da Comissão Européia que impediu qualquer concessão nas negociações da Rodada. Dessa forma, ao mudar o processo para uma unanimidade explícita e diminuir o grau de delegação para a Comissão Européia, os procedimentos internos da Comunidade Econômica Européia contribuíram de forma considerável para que o resultado da Rodada fosse mais favorável à posição mais protecionista existente dentro do bloco europeu.

Na Rodada Uruguai, ocorrência de natureza semelhante voltaria a demonstrar o impacto negativo das instituições domésticas européias nas negociações. De 1986 até 1992, os EUA não conseguiram demover os negociadores europeus de suas posições iniciais de defesa do protecionismo agrícola. Somente com o início da reforma da política agrícola comum de 1992, combinada com uma maior autonomia da Comissão Européia, é que um acordo foi possibilitado na área. A França e demais países mais protecionistas na área, contudo, não ficaram satisfeitos com o resultado final das negociações. Ao lutarem por modificações nos procedimentos internos, conseguiram limitar a autonomia e autoridade da Comissão para negociar externamente e, com isso, reabriram a negociação com os EUA. Com a proximidade 


\section{Resenha}

da expiração da autoridade americana para negociar, o que se encaixa na variável contextual da autora, os negociadores americanos acabaram renegociando certos elementos para acomodar as posições mais protecionistas do bloco europeu (2000:123).

O poder de barganha da União Européia, portanto, não é uma função linear do seu grau de integração. A autora, com sucesso, demonstra que a força externa européia é derivada, em grande medida, dos procedimentos internos que definem a relação de autonomia e autoridade da Comissão Européia perante os membros mais protecionistas do bloco, além do contexto no qual o bloco negocia. A conclusão, para os que desejam mudar as políticas conservadoras da Europa, é, portanto, clara: não é somente o foco nas coalizões de interesses domésticos, como poderia ser deduzido de Robert Strauss, que é relevante para entender e poder fortalecer tendências liberalizantes no sistema multilateral de comércio. Deve-se acreditar, logo, que a estrutura institucional da União Européia, por suas implicações na negociação de acordos comerciais internacionais, é bastante relevante para gerar o coeficiente de força necessário para se alcançar resultados menos protecionistas nas negociações do sistema GATT/OMC.

\section{Referências Bibliográficas}

AARONSON, Susan Ariel. (1996), Trade and the American Dream: A Social History of Postwar Trade Policy. Lexington, The University Press of Kentucky.

BLAKER, Michael et alii. (1978), The Politics of Trade: US and Japanese Policymaking for the GATT Negotiations. New York, The East Asian Institute.

CAPLING, Ann. (2001), Australia and the Global Trade System: From Havana to Seattle. Cambridge, Cambridge University Press. 
DAVIS, Christina L. (2003), Food Fights over Free Trade: How International Institutions Promote Agricultural Trade Liberalization. Princeton, Princeton University Press.

DESTLER, I. M. (1995), American Trade Politics. Washington/New York, Institute for International Economics/Twentieth Century Fund.

DRYDEN, Steve. (1995), Trade Warriors: USTR and the American Crusade for Free Trade. New York, Oxford University Press.

EVANS, John W. (1971), The Kennedy Round in American Trade Policy: The Twilight of the GATT? Cambridge, Harvard University Press.

HART, Michael. (1998), Fifty Years of Canadian Tradecraft: Canada at the GATT (1947-1997). Ottawa, The Centre for Policy and Law.

(2002), A Trading Nation: Canadian Trade Policy from Colonialism to Globalization. Vancouver, UBC Press.

MANYIN, Mark E. (1999), Breaking the Silence: Japan's Behavior in the Tokyo and Uruguay Rounds of the GATT. Tese de Doutorado, Medford, The Fletcher School of Law and Diplomacy.

MEUNIER, Sophie. (2000), "What Single Voice? European Institutions and EU-US Trade Negotiations". International Organization, vol. 54, n ${ }^{\circ}$ 1, pp. 103-135.

. (2003), “Trade Policy and Political Legitimacy”. Comparative European Politics, vol. 1, n 1, pp. 67-90.

e NICOLAIDIS, Kalypso. (1999), "Who Speaks for Europe? The Delegation of Trade Authority in the European Union". Journal of Common Market Studies, vol. 37, n 3, pp. 477-501.

MORAVCSIK, Andrew. (1993), "Introduction: Integrating International and Domestic Theories of International Bargaining”, in P. B. Evans et alii, Double-edge Diplomacy: International Bargaining and Domestic Politics. Los Angeles/Berkeley, University of California Press, pp. 3-42.

NAU, Henry R. (1989), "Domestic Trade Politics and the Uruguay Round: An Overview", in Domestic Trade Politics and the Uruguay Round. New York, Columbia University Press, pp. 1-27. 
PREEG, Ernest H. (1970), Traders and Diplomats: An Analysis of the Kennedy Round of Negotiations under the General Agreement on Tariffs and Trade. Washington, The Brookings Institution.

SEARIGHT, Amy E. (1999), MITI and Multilateralism: The Evolution of Japan's Trade Policy in the GATT Regime. Tese de Doutorado, Stanford, Stanford University.

STONE, Frank. (1984), Canada, the GATT and the International Trade System. Quebec, The Institute for Research on Public Policy.

STRAUSS, Robert S. (1987), "Foreword", in J. E. Twiggs, The Tokyo Round of Multilateral Trade Negotiations: A Case Study in Building Domestic Support for Diplomacy. Washington, D. C., Lanham, University Press of America, pp. vii-xii.

VAHL, Remco. (1997), Leadership in Disguise: The Role of the European Commission in EC Decision-making on Agriculture in the Uruguay Round. Aldershot, Ashgate.

WINHAM, Gilbert. (1986), International Trade and the Tokyo Round Negotiation. Princeton, Princeton University Press. 